\title{
Tipaģem e Estado Físico de Papilomaviris Humano por Hibridização in situ em Lesões Intra-epiteliais do Colo Uterino
}

\author{
Human Papillomavirus Typing and Physical State by \\ in situ Hybridization in Uterine Cervix Intraepithelial Lesions \\ Lúcia Buchalla Bagarelli, Antonio Hélio Oliani
}

\begin{abstract}
RESUMO
Objetivo: realizar estudo molecular (hibridização in situ) de pacientes com lesões intraepiteliais do colo uterino, visando investigar a freqüência e o estado fisico do papilomavírus humano (HPV).

Métodos: cortes histológicos de biopsias do colo uterino de 84 pacientes foram avaliados pela hibridização in situ, com sonda de amplo espectro, que permite identificação dos HPVs dos tipos $6,11,16,18,31,33,35,39,42,45$ e 56, e com sondas específicas para HPV dos tipos $6,11,16,18,31$ e 33. Os padrões físicos de marcação do DNA dos HPV encontrados foram: epissomal, quando todo o núcleo ficou corado pela biotina (marrom); integrado, onde se visualizaram um ou dois pontos marrons no núcleo hibridizado, ou misto, com a associação dos dois padrões anteriores. Das 84 pacientes avaliadas, 31 (36,9\%) tinham lesões intraepiteliais de baixo grau (LIE-BG) e 53 (63,1\%) tinham lesões intra-epiteliais de alto grau (LIE-AG) ao exame histológico. Para a análise estatística foi empregado o teste exato de Fisher. Resultados: do total dos casos, 46 (54,7\%) foram positivos para DNA de HPV pela sonda de amplo espectro. Na tipagem dos vírus, o HPV-16 foi mais freqüente nas LIE-AG, com 12 casos - 22,6\% (p<0,05). As freqüências dos outros tipos de HPV não foram diferentes entre os casos com LIE-BG e LIE-AG. Na avaliação do estado fisico do DNA de HPV, os percentuais de padrões epissomais (mais comum nas LIE-BG) e integrados não foram diferentes entre os dois grupos. Houve predomínio do tipo misto nas LIE-AG em relação às LIE-BG: $26,4 \%$ e $3,2 \%$, respectivamente $(p<0,01)$. O estado fisico do DNA do HPV, integrado ao da célula hospedeira, foi mais freqüente nos casos mais graves.

Conclusões: o HPV-16 foi o mais freqüente nas LIE-AG. As freqüências dos outros tipos de HPV não foram diferentes quando se compararam os casos com LIE-BG e LIE-AG. O estado fisico do DNA do HPV, integrado ao da célula hospedeira, foi mais freqüente nos casos mais graves.
\end{abstract}

PALAVRAS-CHAVE: Papilomavírus humano. Colo do útero: lesões pré-neoplásicas. Hibridização in situ.

Departamento de Ginecologia e Obstetrícia da Faculdade de Medicina de São José do Rio Preto (FAMERP).

Correspondência:

Lúcia B. Bagarelli

R. José Silva Amaral Salles, 1772

15025-450 - São José do Rio Preto - SP

Fones: (17) 232-6470 e 233-6245 - Fax: 233-6245

e-mail: lubaga@terra.com.br

Estudo financiado pela Bolsa de Auxílio à Pesquisa da

Faculdade de Medicina de São José do Rio Preto - FAMERP
Introdução

Atualmente, a associação da infecção pelo papilomavirus humano (HPV) com lesões intraepiteliais de colo, vagina e vulva e com carcinomas escamosos invasores é fato amplamente aceito $^{1-3}$. Dos mais de 100 tipos de HPV existentes, aproximadamente 40 afetam o trato genital hu- 
mano, e destes, 10 a 15 estão associados à carcinogênese cervical. Os HPVs de baixo risco $(6,11,30,42,43$ e 44) são encontrados em lesões intra-epiteliais de baixo grau (LIE-BG). Os HPVs de médio risco $(31,33,35,39,51,52,58$ e 61) são mais encontrados em lesões intra-epiteliais de alto grau (LIE-AG) e, com menor freqüência, em cânceres. Os HPVs de alto risco (16, 18, 45 e 56) são encontrados em LIE-AG e em cânceres cervicais que se apresentam sempre como lesões monoclonais $^{4,5}$.

Quando o HPV infecta a célula, pode ser eliminado, ficar latente ou produzir infecção clínica ou subclínica ativa (DNA viral não integrado epissomal) ou, ainda, integrar seu genoma ao da célula hospedeira imatura, impedindo a diferenciação e maturação celular. A célula transformada não produz mais o vírus, porém, contém o DNA viral $^{1,3,5}$. Segundo zur Hausen ${ }^{1}$, a integração do genoma viral ao da célula hospedeira deve-se à ação de cocarcinogênios iniciantes ou promotores (genéticos, químicos, imunológicos, infecciosos). Infecção persistente por 10 a 20 anos permite o desenvolvimento de alterações genéticas adicionais e progressão de lesões de baixo, moderado e alto grau para câncer invasor ${ }^{5}$.

O tipo de HPV, a carga viral e a detecção persistente do HPV são marcadores importantes para o risco de progressão para o câncer invasor. Lesões causadas por HPV-16 têm risco cinco vezes maior para progredir em comparação com lesões causadas por outros tipos oncogênicos de HPV ${ }^{3,6}$. Brisson et al. ${ }^{6}$ referem risco relativo oito vezes maior para LIE-AG provocadas pelo HPV-16.

A hibridização in situ (HIS) detecta seqüências específicas de DNA ou RNA, utilizando-se seqüência complementar de ácidos nucléicos (sonda) marcada radioativa ou quimicamente. Métodos mais recentes de amplificação dos sinais de detecção utilizando a deposição de catalisador nos sítios de hibridização com deposição de tiramida biotinilada no tecido ${ }^{7,8}$ aumentaram a sensibilidade da HIS, sendo possível detectar até uma única cópia viral por célula e permitindo a avaliação do estado físico (epissomal ou integrado ao genoma do hospedeiro) do HPV. A HIS também possibilita estabelecer a correlação com os aspectos histopatológicos ${ }^{7,8}$.

Em vista da importante participação do HPV na carcinogênese cervical, propusemo-nos a realizar estudo por HIS de lesões intra-epiteliais do colo uterino, com o objetivo de avaliar a freqüência, tipos mais freqüentes e o estado físico do DNA do HPV em pacientes atendidas em nosso serviço.

\section{Pacientes e Métodos}

Foram incluídas, prospectivamente, 84 pacientes atendidas no Serviço de Ginecologia e Obstetrícia do Hospital de Base da Faculdade de Medicina de São José do Rio Preto (FAMERP), no período de novembro de 1996 a novembro de 2002 . Estas pacientes foram encaminhadas para colposcopia e biopsia do colo uterino devido a alterações em seus exames colpocitológicos. Após os resultados anatomopatológicos das biopsias, as pacientes foram divididas em dois grupos de estudo: pacientes com lesão intra-epitelial de baixo grau (NIC-I) - 31 casos (36,9\%), e com lesão intra-epitelial de alto grau (NIC-II e NIC-III) - 53 casos $(63,1 \%)$.

O estudo de HIS para DNA de HPV foi realizado com uso do sistema Dako Genpoint. Tal técnica consiste na detecção, em cortes histológicos de material fixado em formol, de pequenos segmentos de DNA a partir de sondas específicas, que são seqüências de nucleotídeos complementares desenvolvidos a partir de segmentos conhecidos do DNA ou RNA que se deseja identificar. Cada sonda hibridiza uma região de 7,9 quilobases de pares de DNA. Nesta HIS, as sondas estavam associadas a moléculas sinalizadoras não isotópicas biotiniladas e os sítios de ligação, no núcleo das células, puderam ser localizados por reações de imuno-histoquímica, nas quais a enzima reagiu com um substrato cromógeno (diaminobenzidina), que permitiu a vizualização da reação pela coloração marrom ao microscópio óptico. A contracoloração foi feita com hematoxilina.

Considerou-se HIS positiva quando, aproximadamente, $25 \%$ das células apresentaram-se coradas com a biotina. Os padrões físicos de marcação do DNA do HPV foram: difuso ou epissomal, quando todo o núcleo ficou marrom (significa que o DNA do HPV não encontrava-se incorporado ao DNA da célula hospedeira); integrado ou em ponto, quando se visualizaram um ou dois pontos marrons por núcleo hibridizado (significa que houve integração do DNA do HPV ao da célula hospedeira), ou misto, com a associação dos dois anteriores (v. Figura 1).

Utilizamos sonda de amplo espectro, que permite a identificação de 11 tipos de DNA de $\operatorname{HPV}(6,11,16,18,31,33,35,39,42,45$ e 56), e sondas específicas para HPV $6,11,16,18,31$ e 33 para cada caso do estudo. Todos os procedimentos foram acompanhados por controles de células positivos e negativos. Os controles positivos foram obtidos de linhagem celular de carcinoma cervical SiHa, que contém baixo número de cópias de DNA integrado (uma ou duas) do HPV- 16 por célula ${ }^{7}$. 
Para análise estatística foi empregado o teste exato de Fisher para proporções. Foram estimados percentuais e médias na forma pontual e por intervalo de $95 \%$ de confiança.

Este projeto foi aprovado pela Comissão de Ética em Pesquisa da Faculdade de Medicina de São José do Rio Preto (FAMERP).

\section{Resultados}

Dos 84 casos, $46(54,8 \%)$ foram considerados positivos pela HIS com a sonda de amplo espectro, sendo 13 casos $(41,9 \%)$ de LIE-BG e 33 casos $(62,3 \%)$ de LIE-AG (Tabela 1$)$.

Tabela 1 - Freqüência de DNA de HPV pela HIS com sonda biotinilada de amplo espectro (HPV-6, 11, 16, 18, 31, 33, 35, 39, 42, 45 e 56) em pacientes com lesões intra-epiteliais cervicais de baixo grau (LIE-BG) e alto grau (LIE-AG)

\begin{tabular}{lcrrrrr}
\hline DNA de HPV & \multicolumn{2}{c}{ LIE-BG } & \multicolumn{2}{c}{ LIE-AG } & \multicolumn{2}{c}{ Total } \\
& $\mathbf{n}$ & $\%$ & $\mathbf{n}$ & $\%$ & $\mathbf{n}$ & $\%$ \\
\hline Positivo & 13 & 41,9 & 33 & 62,3 & 46 & 54,8 \\
Negativo & 18 & 58,1 & 20 & 37,7 & 38 & 45,2 \\
Total & 31 & 100,0 & 53 & 100,0 & 84 & 100,0
\end{tabular}

HIS = hibridização in situ

Diferenças sem significância estatística pelo teste exato de Fisher

Os casos com resultado positivo pela sonda de amplo espectro e negativos na tipagem viral foram classificados como HPV de outro tipo. Estes foram os mais freqüentes nos grupos de estudo, tendo aparecido em 11 casos $(20,7 \%)$ nas LIE-AG e 4 casos $(12,9 \%)$ nas LIE-BG, porém sem diferença significante. O HPV-16 foi mais freqüente nas LIE-AG: 12 casos $(22,6 \%)$ nas LIE-AG e um $(3,2 \%)$ nas LIE-BG $(p<0,05)$. Outros tipos de HPV apareceram em menor número de casos e não houve diferenças significantes entre os grupos de estudo (Tabela 2).

Tabela 2 - Freqüência de DNA de HPV pela HIS com sondas biotiniladas específicas para detecção de HPV-6, 11, 16, 18, 31 e 33 em pacientes com lesões intra-epiteliais cervicais de baixo grau (LIE-BG) e alto grau (LIE-AG).

\begin{tabular}{lrrrrrr}
\hline DNA de HPV & \multicolumn{2}{c}{ LIE-BG } & \multicolumn{2}{c}{ LIE-AG } & \multicolumn{2}{c}{ Total } \\
& $\mathbf{n}$ & $\%$ & $\mathbf{n}$ & $\%$ & $\mathbf{n}$ & $\%$ \\
\hline HPV-6 & 2 & 6,4 & 1 & 1,9 & 3 & 3,6 \\
HPV-11 & - & - & - & - & - & - \\
HPV-16* & 1 & 3,2 & 12 & 22,6 & 13 & 15,5 \\
HPV-18 & 3 & 9,7 & 5 & 9,4 & 8 & 9,5 \\
HPV-31 & 3 & 9,7 & 3 & 5,7 & 6 & 7,1 \\
HPV-33 & 2 & 6,4 & 5 & 9,4 & 7 & 8,3 \\
HPV de outro tipo & 4 & 12,9 & 11 & 20,7 & 15 & 17,9 \\
Negativo & 18 & 58,1 & 20 & 37,7 & 31 & 45,2 \\
\hline *p<0.05 (teste exato de Fisher) & \multicolumn{4}{c}{ HIS = hibridização in situ }
\end{tabular}

Na avaliação do estado físico do DNA do HPV, do total de 84 pacientes, encontramos: 15 casos $(17,9 \%)$ com padrão misto de DNA de HPV, sendo um $(3,2 \%)$ nas LIE-BG e $14(26,4 \%)$ nas LIE-AG $(\mathrm{p}<0,01)$. Nove casos $(10,7 \%)$ apresentaram padrão epissomal, sendo $4(12,9 \%)$ nas LIE-BG e $5(9,4 \%)$ nas LIE-AG. Vinte e dois casos $(26,2 \%)$ tinham DNA de HPV integrados sendo $8(25,8 \%)$ nas LIE-BG e $14(26,4 \%)$ nas LIE-AG (Tabela 3). Considerando apenas os casos positivos, do total de 46 pacientes, encontramos 15 casos $(32,6 \%)$ com padrão misto de DNA de HPV, sendo um $(7,7 \%)$ nas LIEBG e $14(42,4 \%)$ nas LIE-AG. Nove casos $(19,6 \%)$ apresentaram padrão epissomal, sendo 4 (30,8\%) nas LIE-BG e $5(15,2 \%)$ nas LIE-AG. Vinte e dois casos $(47,8 \%)$ tinham DNA de HPV integrado, sendo $8(61,5 \%)$ nas LIE-BG e $14(42,4 \%)$ nas LIE-AG.

Tabela 3 - Freqüência do estado físico do DNA de HPV pela hibridização in situ em pacientes com lesões intra-epiteliais cervicais de baixo grau (LIE-BG) e alto grau (LIE- AG).

\begin{tabular}{lrrrrrr}
\hline $\begin{array}{l}\text { Padrão físico } \\
\text { Do DNA de HPV }\end{array}$ & \multicolumn{2}{c}{ LIE-BG } & \multicolumn{2}{c}{ LIE-AG } & \multicolumn{2}{c}{ Total } \\
& $\mathbf{n}$ & $\%$ & $\mathbf{n}$ & $\%$ & $\mathbf{n}$ & $\%$ \\
\hline Misto** & 1 & 3,2 & 14 & 26,4 & 15 & 17,9 \\
Epissomal & 4 & 12,9 & 5 & 9,4 & 9 & 10,7 \\
Integrado & 8 & 25,8 & 14 & 26,4 & 22 & 26,2 \\
Negativo & 18 & 58,1 & 20 & 37,8 & 38 & 45,2 \\
Total & 31 & 100,0 & 53 & 100,0 & 84 & 100,0 \\
**p<0,01 (teste exato de Fisher) & \multicolumn{5}{c}{ HIS = hibridização in situ }
\end{tabular}

Os núcleos com DNA de HPV em forma epissomal foram mais encontrados nos coilócitos e nas camadas mais superficiais do epitélio. Já os padrões integrados foram encontrados com maior freqüência nas áreas mais profundas e com atipias celulares.

A Figura 1 mostra os padrões físicos do DNA do HPV em cortes histológicos de lesões intraepiteliais do colo uterino.

\section{Discussão}

A HIS é considerada método de boa especificidade, porém de baixa sensibilidade. Segundo Tyring ${ }^{3}$, a sensibilidade da HIS permite a detecção de 10.000 cópias de HPV por célula. No entanto, a sensibilidade difere de acordo com a técnica utilizada. Técnicas mais recentes, como a utilizada neste estudo, permitem a amplificação dos sinais de detecção, aumentando a sensibilidade em cerca de cem mil vezes, sendo possível a detecção de apenas uma cópia viral por célula ${ }^{8}$. 

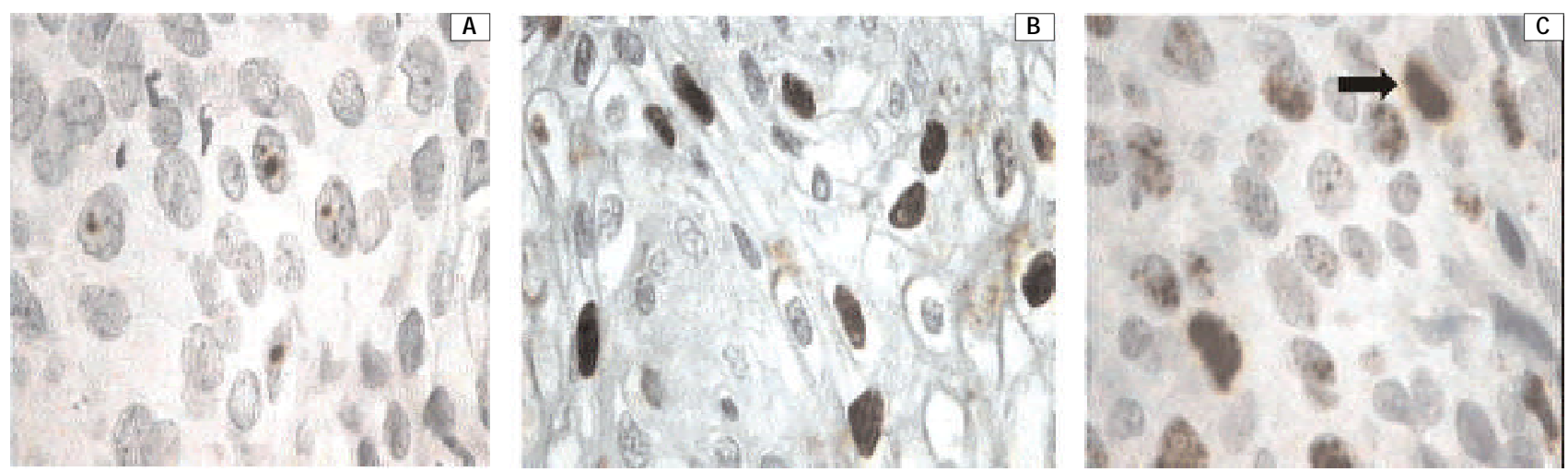

Figura 1 - Estado físico do DNA do HPV pela HIS em cortes histológicos de lesões intra-epiteliais do colo uterino. Em (A), padrão integrado (seta fina); em (B), padrão epissomal (seta larga) e em (C), padrão misto (integrado - seta fina e epissomal - seta larga). (Aumento de 400X).

HIS = hibridização in situ.

Observamos que 54,8\% dos casos eram positivos pela HIS. Este percentual é mais alto do que o encontrado por Melchers et al. ${ }^{9}(46 \%)$ e inferior ao de Gómez et al. ${ }^{10}(69 \%)$ e de Lörincz et al. ${ }^{11}$ $(79,3 \%)$, sendo que este último incluiu, além das LIE, carcinomas escamosos do colo.

Entre os casos com LIE-BG, 41,9\% eram positivos para HPV. Este resultado é próximo ao mencionado por Anderson et al. ${ }^{12}$ (52\%) e abaixo do encontrado por Nuovo et al. ${ }^{13}(72 \%)$, Richart e Nuovo $^{14}(91 \%)$, Gómez et al. ${ }^{10}(65,4 \%)$ e Cavalcanti et al. ${ }^{15}$ (85,6\%). A baixa sensibilidade da HIS explica os baixos percentuais encontrados por nós nas LIE-BG, sabidamente causadas por HPV, nas quais o padrão epissomal de DNA de HPV deveria ter sido detectado mais vezes.

Entre os casos com LIE-AG, 62,3\% eram positivos, cifra pouco inferior à encontrada por Fallani et al. ${ }^{16}(80 \%)$, Gómez et al. ${ }^{10}(78,4 \%)$ e Anderson et al. ${ }^{12}$ (67\%).

$\mathrm{Na}$ tipagem dos vírus, observamos maior freqüência de HPV-16 no grupo das LIE-AG, o que esteve de acordo com a maioria dos estudos ${ }^{11,13,15,16}$. Os outros tipos de HPV estiveram presentes em proporções semelhantes nos grupos de estudo. O HPV tipo 18 apareceu nos dois grupos de estudo, geralmente em área de displasia dentro de glândulas endocervicais que sofreram metaplasia escamosa. Este achado também esteve de acordo com outros estudos que mostraram predileção do HPV-18 pelo tecido glandular. O HPV-11 não foi detectado, o que é surpreendente, pois esperavase encontrá-lo em casos de LIE-BG. Tal fato, talvez, deva-se aos pequenos números da amostra estudada, além da baixa sensibilidade do método.

Encontramos as três formas de estado físico do HPV. O epissomal predominou no grupo de pacientes com LIE-BG, porém a diferença não foi significante. Os casos com padrão integrado de DNA de HPV foram encontrados nos dois grupos em porcentagens semelhantes, já o padrão misto foi mais freqüente nos casos de LIE-AG. Assim como nós, Durst et al. ${ }^{17}$, Nagai et al. ${ }^{18}$, Skyldberg et al. ${ }^{19}$, Gómez et al. ${ }^{10}$ e Pirami et al. ${ }^{20}$ observaram maior freqüência de DNA de HPV epissomal nos coilócitos e nas camadas mais superficiais do epitélio, e integrado, nas áreas mais profundas e com atipias celulares.

Considerando somente os casos positivos, os padrões integrados (somados os isolados e os mistos) foram observados nas LIE-BG em 69,2\% e nas LIE-AG em 84,8\% dos casos. Gómez et al. ${ }^{10} \mathrm{e}$ Pirami et al. ${ }^{20}$ também observaram maior freqüência de integração do DNA do HPV nas LIE-AG, o que reforça a noção de que a integração seja fator de risco para a progressão da lesão.

Quando relacionamos o tipo de HPV com o achado histopatológico, encontramos a maior porcentagem de HPV-16 nos casos mais graves (92\% nas LIE-AG). No caso do HPV-18, encontramos $62 \%$ deles nas LIE-AG, o que reforça a noção, já bem divulgada em vários estudos, de seu potencial oncogênico como tipo de alto risco, junto com o HPV-16. Os HPVs de médio risco (31 e 33) também foram mais freqüentes nas LIE-AG e o HPV-6 apareceu apenas em três casos, todos nos coilócitos superficiais, em estado epissomal, já que é HPV de baixo risco. Estes achados estiveram de acordo com os de vários autores ${ }^{11,12,16,18,21-24}$.

A identificação de DNA de HPV de alto risco (principalmente HPV-16 e 18) permite a seleção daquelas mulheres com real risco de câncer cervical. Diante de paciente com diagnóstico suspeito de HPV pelos métodos tradicionais, a realização de exames de hibridização molecular poderia auxiliar no diagnóstico, principalmente para o reconhecimento de HPVs do grupo de alto risco ${ }^{25}$. 
Esses testes têm valor, também, para seguimento após tratamento e para o prognóstico dos casos. Devido à baixa sensibilidade da HIS, ela tem sido substituída pela captura híbrida, que permite detectar o tipo de HPV e sua carga viral.

Concluímos que, na comparação entre os grupos, pacientes portadoras de LIE-AG apresentaram, com maior freqüência, o HPV-16, assim como o padrão misto (epissomal e integrado juntos) de DNA do HPV. Apesar da boa especificidade, a HIS mostrou-se método de baixa sensibilidade neste estudo. Sempre que possível, deverá ser substituído por outro mais sensível.

\section{ABSTRACT}

Purpose: to carry out a molecular study (in situ hybridization) on patients who present intraepithelial lesions of the uterine cervix, and to assess the frequency and the physical state of the human papillomavirus (HPV).

Methods: histological sections of biopsies of the uterine cervix from 84 patients were evaluated by in situ hybridization, with a broad-spectrum probe, which allows the identification of the HPV types 6, 11, 16, 18, 31, 33, 35, $39,42,45$, and 56 and with specific probes for HPV types 6 , $11,16,18,31$, and 33. The physical patterns of HPV DNA found were: episomal, when the entire nucleus stains with biotin (brown); integrated - one or two brown points in the hybridized nucleus, or mixed, associating both patterns. Of the 84 patients evaluated, 31 (36.9\%) had low-grade squamous intraepithelial lesions (LSIL), and 53 (63.1\%) had high-grade squamous intraepithelial lesions (HSIL) on histological examination. Fisher's exact test was used for the statistical analysis.

Results: considering all the cases, 46 (54.7\%) were positive for HPV DNA with the broad-spectrum probe. Regarding typing, HPV-16 was the most frequent in HSIL (12 cases $22.6 \%$ - $p<0.05)$. The frequencies of the other HPV types did not show statistically significant differences between the LSIL and HSIL cases. By physical condition assessment of the HPV DNA, the percentage of the episomal (most common in LSIL) and integrated patterns showed no significant differences between the two groups; the mixed HSIL type prevailed when compared to LSIL: 26.4 and $3.2 \%$, respectively ( $p<0.01)$. The physical condition of the HPV DNA, integrated in the host cell, was more frequent in the most severe cases. Conclusions: HPV-16 was the most frequent in HSIL cases. The frequencies of the other HPV types did not show statistically significant differences between the LSIL and HSIL cases. The physical condition of the HPV DNA, integrated in the host cell, was more frequent in the more severe cases.

KEYWORDS: Human papillomavirus. HPV. Cervix: intraepithelial lesion. In situ hybridization.

\section{Agradecimentos}

Aos Prof. Dr. José Focchi, Prof. Dr. Reinaldo Azoubel, Profa. Dra. Sueli Suzigan, Prof. Dr. José Antonio Cordeiro, Profa. Marli Nogaroto e Profa. Vera Lúcia Buchalla, pelos auxílios para a realização deste estudo.

\section{Referências}

1. zur Hausen H. Papillomaviruses and cancer: from basic studies to clinical application. Nat Rev Cancer 2002; 2:342-50.

2. Feichter G, Meisels A. Task force consensus report on HPV-related changes of the lower female genital tract. Acta Cytol 2002; 46:630-2.

3. Tyring SK. Human papillomavirus infections: epidemiology, pathogenesis and host immune reponse. J Am Acad Dermatol 2000; 43:S18-26.

4. Bagarelli LB, Oliani AH. Infecção por papilomavírus humano (HPV) e neoplasias do colo uterino. HB Cient 1997; 4:31-49.

5. Pereyra EG, Parellada CI, Chuery ACS. Papilomavírus humano. In: Martins NV, Pereyra EG, editores. Conhecendo o HPV: patologia do trato genital inferior, colposcopia e cirurgia de alta freqüência. $1^{a}$ ed. São Paulo: Frôntis Editorial; 2000. p.1-12.

6. Brisson J, Morin C, Fortier M, et al. Risk factors for cervical intraepithelial neoplasia: differences between low- and high-grade lesions. Am J Epidemiol 1994; 140:700-10.

7. Lancellotti CLP, Levi JE, Silva MALG, Schwarzschild M, Nicolau SM. Diagnóstico laboratorial. In: Carvalho JJM, Oyakama N. Focchi J, editores. I Consenso Brasileiro de HPV-Papilomavírus Humano. $1^{\text {a }}$ ed. São Paulo: BG Cultural; 2000. p.45-60.

8. Villa LL. Biologia Molecular: conceitos e princípios básicos. In: Martins NV, Pereyra EG, editores. Conhecendo o HPV: patologia do trato genital inferior, colposcopia e cirurgia de alta freqüência. $1^{a}$ ed. São Paulo: Frôntis Editorial; 2000. p.137-44.

9. Melchers W, van den Brule A, Walboomers J, et al. Increased detection rate of human papillomavirus in cervical scrapes by the polymerase chain reaction as compared to modified FISH and southern-blot analysis. J Med Virol 1989; 27:329-35.

10.Gómez F, Picazo A, Roldán M, et al. Labelling pattern obtained by non-isotopic in situ hybridization as a prognostic factor in HPV-associated lesions. J Pathol 1996; 179:272-5. 
11.Lörincz AT, Reid R, Jenson AB, Greenberg MD, Lancaster W, Kurman RJ. Human papillomavirus infection of the cervix: relative risk associations of 15 common anogenital types. Obstet Gynecol 1992; 79:328-37.

12.Anderson SM, Brooke PK, van Eyck SL, Noell H, Frable WJ. Distribution of human papillomavirus types in genital lesions from two temporally distinct populations determined by in situ hybridization. Hum Pathol 1993; 24:547-53.

13. Nuovo GJ, Friedman D, Richart RM. In situ hybridization analysis of human papillomavirus DNA segregation patterns in lesions of the female genital tract. Gynecol Oncol 1990; 36:256-62.

14. Richart RM, Nuovo GJ. Human papillomavirus DNA in situ hybridization may be used for the quality control of genital tract biopsies. Obstet Gynecol 1990; 75:223-6.

15.Cavalcanti SM, Zardo LG, Passos MR, Oliveira LH. Epidemiological aspects of human papillomavirus infection and cervical cancer in Brazil. J Infect 2000; 40:80-7.

16.Fallani MG, Pirami L, Penna C, et al. Cervical intraepithelial neoplasia (CIN) and human papillomavirus (HPV) infection. Minerva Ginecol 1997; 49:13-8.

17.Durst M, Glitz D, Schneider A, zur Hausen H. Human papillomavirus type 16 (HPV 16) gene expression and DNA replication in cervical neoplasia: analysis by in situ hybridization. Virology 1992; 189:132-40.
18.Nagai N, Nuovo G, Friedman D, Crum CP. Detection of papillomavirus nucleic acids in genital precancers with the in situ hybridization technique. Int $\mathrm{J}$ Gynecol Pathol 1987; 6:366-79.

19.Skyldberg B, Kalantari M, Karki M, Johansson B, Hagmar B, Walaas L. Detection of human papillomavirus infection in tissue blocks by in situ hybridization as compared with a polymerase chain reaction procedure. Hum Pathol 1991; 22:578-82.

20.Pirami L, Giachè V, Becciolini A. Analysis of HPV16, 18,31 , and 35 DNA in pre- invasive and invasive lesions of the uterine cervix. J Clin Pathol 1997; 50:600-4.

21.Blessing K, McLaren KM, Morris R, et al. Detection of human papillomavirus in skin and genital lesions of renal allograft recipients by in situ hybridization. Histopathology 1990; 16:181-5.

22.Leu FJ, Shih CM, Choo KB. Detection of human papillomavirus DNA in human cervical lesions by tissue in situ nucleic acid hybridization. J Formos Med Assoc 1990; 89:949-54.

23.Nuovo GJ, Pedemonte BM. Human papillomavirus types and recurrent cervical warts. JAMA 1990; 263:1223-6.

24.Autillo-Touati A, Joannes M, d'Ercole C, et al. HPV testing by in situ hybridization on cervical cytologic smears with ASCUS. Acta Cytol 1998; 42:631-8.

25. Focchi J, Bovo AC, Silva IDCG. Papilomavírus humano (HPV). J SOGESP 1999; 10:61-2.

Recebido em: 19/5/2003 Aceito com modificações em: 27/11/2003 